\title{
Nuevos enfoques teológicos sobre la eucaristía
}

\author{
Víctor Codina, S.J., \\ Universidad Católica Boliviana, \\ Centro de Espiritualidad Ignaciana, \\ Cochabamba, Bolivia.
}

La teología de la eucaristía, que desde Trento se había centrado casi exclusivamente en las cuestiones de la presencia real y el sacrificio, ha conocido en los últimos cincuenta años una profunda renovación teológica. Sin duda, el Vaticano II ha sido la fuente principal de esta renovación, sobre todo gracias a la Sacrosanctum Concilium, que ha posibilitado un mejor conocimiento de la eucaristía y una serie de reformas pastorales para dar mayor participación a los fieles.

Pero el Vaticano II fue precedido por una serie de movimientos teológicos, que fructificaron en el concilio, y a su vez, éste abrí la puerta a nuevos aportes teológicos sobre la eucaristŕa. De este modo, se han retomado aspectos de la tradición eclesial del primer milenio, los cuales fueron olvidados en el segundo milenio y que ofrecen nuevas perspectivas para la actualidad.

Los movimientos bíblico, patrístico, litúrgico, ecuménico, eclesiológico y pastoral han renovado la teología de la eucaristía', pero también han contribuido a esa renovación las ciencias humanas, la sociología y la historia. Más recientemente, la perspectiva hermenéutica desde los pobres y del hambre del mundo está enriqueciendo de forma notable la teología eucarística.

La eucaristía es, ciertamente, un misterio, "misterio de fe", como proclamamos después de la consagración. Sin fe no se puede aceptar este misterio. Ya después del discurso de Jesús, en Cafamaum, sobre el pan de vida, muchos discípulos le abandonaron (Jn 6,60-67). Pero la fe pide también un acercamiento racional al

1. B. Sesbolleé, "Eucharistie: deux générations de travaux", Erudes, juillet (1981) 99115, con amplia bibliograffa ; V. Codina, La fracción del pan, Cochabamba, 2002. 
misterio, para que éste pueda ser mejor comprendido y comunicado. Este misterio se hace presente en la celebración de la Iglesia, y por eso, interrogaremos también a la praxis eclesial para comprender mejor este sacramento de la fe.

No pretendemos hacer un análisis exhaustivo de cada uno de estos movimientos teológicos, ni elaborar un boletín bibliográfico completo sobre la eucaristía. Tan sólo quisiéramos presentar los principales resultados de las investigaciones que pueden enriquecer nuestra visión teológica de la eucaristía.

\section{Renovación de los temas clásicos}

Antes de abordar los nuevos enfoques teológicos, queremos señalar, brevemente, la renovación teológica de los temas clásicos: la presencia real y el sacrificio.

El terna de la presencia real ha sido repensado desde categorias más relacionales, personalistas y existenciales. Es lo que se ha llamado "la teología holandesa de la eucaristía"2. Para aquellos teólogos, la transubstanciación era una noción demasiado estática, cosista e hilemórfica, y pensaron que la transfinalización y transignificación del pan y del vino en el cuerpo y sangre de Cristo podian explicar mejor el misterio de la presencia real. Adujeron un ejemplo que se hizo proverbial: el ramo de flores y el anillo que se intercambian los novios en la boda pasan de ser realidades vegetales y minerales a ser signos del amor mutuo de los esposos. Hay una transignificación y una transfinalización, que los transforma profundamente. Lo mismo - dicen - sucede en la eucaristía, cuando el pan y el vino pasan de ser realidades materiales a ser signo de amor y entrega de Jesús.

Esto desencandenó una fuerte polémica teológica, en la cual intervinieron teólogos alemanes como K. Rahner ${ }^{3}$ y Ratzinger ${ }^{4}$. En 1965, en pleno Vaticano II, Pablo VI, en la encíclica Mysterium fidei, quiso dirimir la cuestión y afimnó que el concepto de transubstanciación era apto para la explicación teológica de la presencia real, mientras que los de transignificación y transfinalización, aunque enriquecían la tradición, no eran suficientes para dar cuenta del cambio ontológico de substancia en la eucaristía. Pero es importante recordar que Pablo VI sitúa la presencia real de Cristo en la eucaristía, que es una presencia substancial, dentro del conjunto de otras presencias reales de Cristo en su Iglesia: en la oración de ésta, en la predicación del evangelio, en la autoridad de los pastores y en la celebración de los sacramentos.

2. Una buena exposición de las diferentes posturas se encuentra en J. M. Powers, Teología de la eucaristía, Buenos Aires, 1969, y en M. Gesteira, La eucaristía, misterio de comunión, Madrid, 1983, pp. 521-552.

3. K. Rahner, "La presencia real de Cristo en el sacramento de la cena del Señor", Escritos de Teologia IV, Madrid, 1961, pp. 367-396.

4. J. Ratzinger, "Das Problem der Transubstantiation und die Frage nach den Sinn der Eucharistie", Theol Quart 147 (1967) 153s. 
La clásica noción del sacrificio de Cristo, esencial para comprender la dimensión sacrificial de la eucaristía, también fue revisada. Se pasó del esquema anselmiano del honor de Dios ofendido, que exige reparación condigna y una expiación sangrienta, a una visión de la vida de Jesús como un servicio - diakonía - a la humanidad, como pro-existencia en obediencia al Padre, que no se reduce a su muertes ${ }^{5}$. Más tarde, volveremos sobre este tema al tratar del memorial.

\section{Las comidas de Jesús}

Para comprender mejor este apartado, hemos de partir de una comprensión más plena de lo que significa el simbolismo eucarístico. Se suele decir que el simbolismo de la eucaristía se centra en el pan y el vino, pero, sin que esto sea falso, es necesaria una mayor precisión. Los símbolos sacramentales no son cosas, sino acciones y relaciones humanas. El sentido pleno del simbolismo eucarístico nace de la idea de comida, de convite, de banquete. No es simplemente el pan, sino el pan partido, repartido y compartido. No es simplemente el vino, sino la copa de vino compartida entre los comensales, reunidos en torno a la mesa. El mismo Juan Pablo П, en su carta apostólica Mane nobiscum Domine, con motivo del año eucarístico, afima:

No hay duda que el aspecto más evidente de la eucaristía es el de banquete. La eucaristía nació la noche del jueves santo en el contexto de una cena pascual. Por tanto, conlleva en su estructura el sentido del convite: "Tomad, comed...Tomó luego la copa y se la dio diciendo: bebed de ella todos" (Mt $26,26.27)^{6}$

Esto, evidentemente, no niega ni la dimensión sacrificial, ni tampoco el culto eucarístico, que fue defendido por Pablo VI, en Eucharisticum mysterium (1967), y por Juan Pablo II, en Dominicae coenae (1980). Pero, según sea el sentido del símbolo eucarístico - un objeto o una relación humana - de él se desprenderá una diferente teología de la eucaristía. Y así, esta primera aproximación nos permitirá comprender mejor el significado de los estudios bíblicos, en torno a las comidas de Jesús.

Normalmente, para el estudio de la eucaristía se parte de la institución de la eucaristía, en la última cena; pero los estudios bíblicos, en diálogo con la sociología de la religión, han resaltado la importancia de todas las comidas de Jesús ${ }^{7}$.

5. H. Schürmann, Cómo entendió y vivió Jesuís su muerte, Salamanca, 1982; L. M. Chauvet, Thèmes de reflexión sur l'Eucharistie, Paris, 1981; J. Aldazábal, La eucaristia, Barcelona, 2000, pp. 331-351.

6. Juan Pablo II, Mane nobiscum Domine, 15.

7. Se considera que el primer autor que trató de este tema fue E. Lohmeyer, "Vom urchristlichen Abendmahl", Theologisches Rundschau, Neue Folge 9. (1937) 168227; 273-312; más modernamente, han trabajado este tema R. Aguirre, La mesa com- 
Esta comensalidad de Jesús, que provocó que fuera llamado comilón y borracho (Mt 11, 19) y que escandalizó a los fariseos (Lc 15, 1-2), incluye las comidas con pecadores (Mc 2, 16; Lc 19, 1-10), las comidas en casas de fariseos (LC 7, $35-50 ; 14,37-54)$, las comidas con sus amigos ( $L c$ 10, 38-42; Jn 2, 1-12; 12, 111) y las multiplicaciones de los panes (Mc 6, 34-44; 8, 1-9; Mt 14, 14-21; 15, 32.-38; Lc 9, 1lb-17; Jn 6, 1-15).

¿Qué es lo que subyace a estas comidas? Las comidas son una parábola viva, un signo profético del reino, que muchas veces se representa bajo la forma de banquete (Is 25, 6; Mt 22,1-14; Lc 14, 16-24). Frente al mundo judío que discriminaba a los pecadores, impuros, gentiles y mujeres, y donde los pobres pasaban hambre, Jesús anuncia un reino de misericordia, de inclusión, de fratemidad, de abundancia.

Y estas comidas no se limitan al tiempo del Jesús histórico. Es importante resaltar las comidas del resucitado con sus discípulos (Lc 24, 13-35; 24, 36-52; Jn 21, 12-13; Hech 1, 4; 10,41), donde aparece el Señor, en un clima de gozo y comunidad, con una presencia que viene de la orilla de la escatología, sin poderse distinguir claramente entre presencia del resucitado y la eucaristía. ¿Es una aparición que acaba en eucaristía o es una eucaristía que desemboca en una aparición?

Dentro de este contexto amplio de las comidas de Jesús de Nazaret se enmarca la última cena, una cena de despedida, el testamento de Jesús, que anticipa litúrgicamente su muerte y su resurrección y el banquete escatológico del reino (Lc 22, 14-18; Mc 14, 25). El pan es el cuerpo de Cristo entregado, el vino es la sangre de Cristo derramada.

Las comidas de Jesús, que anuncian el banquete del reino, son de una gran riqueza para comprender mejor la eucaristía, el misterio pascual, la Iglesia y el reino que anuncia el banquete mesiánico, donde los pobres ya no pasarán hambre.

\section{Memorial}

Todo lo dicho hasta ahora se entendería mal, si se pensase que la eucaristía se reduce a una simple reunión alegre y amistosa, a un banquete fratemo, a una fiesta social. La tradición de la Iglesia ha afirmado siempre el carácter sacrificial de la eucaristra, su estrecha relación con la cruz. Tanto se ha resaltado que la eucaristía

partida, Santander, 1994; L. Maldonado, Eucaristía en devenir, Santander, 1997; X. Basurko, Para comprender la eucaristía, Estella, 2000; E. Laverdière, Comer en el Reino de Dios, Santander, 2002; E. J. Hammes, "Piedras en pan ¿Por qué no? Eucaristía/Koinonia", Concilium 310 (2005) 187-197. Para un mayor conocimiento de otros aportes bfblicos sobre la eucaristía, se puede acudir a X. Léon-Dufour, La fracción de pan, Madrid, 1983; J. L. Espinel, La Eucaristía del Nuevo Testamenso, Salamanca, 1980. 
es un sacrificio que provocó la reacción de la reforma: afirmar que la eucaristía es sacrificio, iba en contra del dato bíblico de que la cruz es el único sacrificio que nos salva de una vez por todas. Por ello, Trento reafimará que, aunque el sacrificio de Cristo ocurrió una vez en la cruz (semel, DS 1740), sin embargo, se actualiza y prolonga en la Iglesia, a través de la eucaristía (DS 1743) y ésta es verdadero sacrificio (DS 1739-1742). Pero, aunque Trento también insinúa que en la celebración eucarística perdura la memoria de la oblación cruenta de Jesús y es representada la cruz, faltaba profundizar más la relación entre cruz y eucaristía.

Los estudios de Otto Casel (1886-1948) de la abadía benedictina de María Laach sobre el carácter mistérico del culto cristiano permitieron explicar cómo la cruz se actualiza en la celebración de la eucaristía y ofrecieron nuevas pistas a la investigación eucarística, aunque muchas de sus ideas fueron matizadas y corregidas por Pío XII, en Mediator Dei $(1947)^{8}$. Habrá que esperar al estudio clásico de Max Thurian sobre la dimensión bíblica y litúrgica del memorial para poder hallar una explicación satisfactoria de la relación entre eucaristía y cruz".

El término memorial (anámnesis), que aparece en Lucas 22, 19 y 1 Corintios $11,24-25$, cuando Jesús pide que se haga "esto" en memoria suya, queda iluminado, a través de la categoría hebrea de zikkaron. El zikkaron bỉblico es una memoria del pasado, pero que no se reduce al puro recuerdo subjetivo y psicológico de algo que ya sucedio, sino que es una actualización del pasado en el presente. Esto aparece, sobre todo, en la fiesta de la pascua judía, memorial de la gesta de la liberación de la esclavitud de Egipto (Ex 12,14), que revivían, de generación en generación, como si ellos hubiesen salido de aquel país. El memorial hace presente el pasado y espera el cumplimiento escatológico, y en ese sentido, la eucaristía es memorial de la cruz. El único sacrificio de Cristo en la cruz no se repite, sino que se actualiza y se hace presente, a través del ministerio de la Iglesia.

Los padres de la Iglesia intentaron explicar esta actualización de la cruz en la eucaristía, a través de la noción platónica del símbolo real ${ }^{10}$. Santo Tomás aplica a la eucaristía las dimensiones de memorial de la salvación (signum rememorarivum), actualización de la salvación (signum demonstrativum) y anticipación del banquete escatológico del reino (signum prognosticum)". Pero esta visión unitaria se perderá después, en la edad media, lo cual explica que, en el siglo XVI, ni Roma, ni la reforma tuviesen instrumentos teológicos adecuados para explicar plenamente la relación de la eucaristía con la cruz

8. Para conocer la evolución del movimiento litúrgico y el aporte de $\mathrm{O}$. Casel, ver $\mathrm{E}$. Vilanova, Historia de la teologia cristiana, Vol. III, Barcelona, 1989, pp. 602-612.

9. M. Thurian, La eucaristía memorial del Señor, Salamanca, 1967.

10. J. Betz, Die Eucharistie in der Zeit der griechischen Väter, Freiburg i Br, 1955.

11. ST III, q 60, a 3. Cfr. el himno de la liturgia de la fiesta del Corpus: "Recolitur memoria passionis eius, mens impletur gratia et futurae gloriae nobis pignus datur". 
El redescubrimiento, en nuestros días, de la noción bíblica de memorial tiene gran importancia ecuménica, pues permite articular de forma unitaria la eucaristía. Y además, la categoría de memorial hace de la eucaristía una memoria subversiva y peligrosa (J. B. Metz): es el recuerdo vivo de un ajusticiado, que muere a consecuencia de sus opciones históricas liberadoras.

\section{Sacramento pascual}

Mientras la tradición ha subrayado la relación entre eucaristía y cruz y ha visto en la eucaristía un memorial de la pasión, dejó en penumbra su relación con la resurrección. Esta dimensión de la totalidad del misterio pascual -muerte y resurrección - ha sido subrayada, en los últimos tiempos, por varios té́logos ${ }^{12}$. La eucaristía es memorial no sólo de la pasión, sino de la totalidad del misterio de Cristo, e incluso anticipa el futuro escatológico, tema muy presente en las comunidades cristianas primitivas, que esperaban gozosa y ansiosamente la vuelta del Señor.

Para F. X. Durrwell, cuya cristología ha puesto de relieve la importancia salvífica de la resurrección ${ }^{13}$, la eucaristía es el sacramento de la pascua de Jesús. La eucaristía no se puede entender, según Durrwell, desde la distinción aristotélica entre substancia y accidentes, ni tampoco desde las modernas teorlas de la transfinalización y transignificación. En la eucaristía, el cambio no es entre realidades terrenas, ni humanas, sino escatológico: se hace presente el Señor resucitado, que es nuestra salvación, lo último y definitivo. La eucaristía es una forma permanente de aparición pascual, es la presencia del éschaton, en nuestro mundo. El pan y el vino alcanzan su plenitud escatológica, se convierten en pan verdadero y vino del reino. No hay que decir, como en la escolástica, que permanecen unos accidentes como despojos vacíos de contenido, sino que el pan y el vino son escatologizados. El pan y el vino no desaparecen, se convierten en Pan y Vino del Reino que da vida. Es el comienzo de la explosión de la parusía, la cumbre del simbolismo cósmico, "la misa del mundo" de la que hablaba Teilhard de Chardin, el comienzo de los nuevos cielos y la nueva tierra. Y todo ello a causa de la presencia del resucitado, una presencia que viene del fin, de la orilla de la escatología.

La riqueza de esta visión teológica consiste en que abre la eucaristía no sólo a la Iglesia, sino al cosmos, y tiene consecuencias para una perspectiva ecológica de la eucaristía ${ }^{14}$. Esta dimensión pascual ya ha pasado a formar parte de los actuales tratados eucarísticos ${ }^{15}$.

12. F. X. Durrwell, La eucaristia, sacramento pascual, Salamanca, 1982; J. M. R. Tillard, L'eucharistie, pâque de l'Eglise, París, 1964; G. Martelet, Resurrection, eucharistie et genèse de I homme, París, 1972.

13. F. X. Durrwell, La resurrección de Jesús misterio de salvación, Barcelona, 1962 .

14. J. Carrera, J. I. González Faus, Horizonse Kyoto. El problema ecológico, Cuademos Cristianisme i justicia, 133, Barcelona, 2005, pp. 22-23.

15. Ver J. Aldazábal, La eucaristía, Barcelona, 2000, pp. 284s M. D. Borobio, Eucaristía, Madrid, 2000, pp. 151-181. 


\section{Epiclesis}

La Iglesia antigua, sobre todo la oriental, ha concedido mucha importancia a la epíclesis en su teología y praxis sacramental. La epíclesis es la invocación al Espíritu para que realice el misterio de salvación, que se significa en el sacramento. La epíclesis alcanza su punto álgido en la eucaristía, donde la Iglesia pide la fuerza del Espíritu para que transforme el pan y el vino, en el cuerpo y la sangre del Señor y transforme a los participantes, en el cuerpo eclesial del Señor.

La Iglesia oriental, siempre sensible al Espíritu, ha expresado esta fe pneumatologica en la liturgia eucarística, acentuando explícitamente esta epíclesis o invocación al Espíritu. Más aún, oriente concede a la epíclesis la primacía en la consagración del pan y el vino, en el cuerpo y la sangre del Señor. Y teólogos ortodoxos modemos, como Paul Evdokimov, consideran que la epíclesis expresa litúrgicamente el gran principio teológico de que el Espíritu precede a toda cristofanía. Esto se cumple en el Antiguo Testamento, y de forma singular en el nacimiento de Jesús de María virgen, por obra del Espíritu, y también en pentecostés, cuando nace la Iglesia, que es el cuerpo de Cristo en la historia. Hay una íntima relación entre cristologla y pneumatología, que expresa la unión y reciprocidad entre el Hijo y el Espíritu ${ }^{16}$. De este modo, la eucaristía deja de ser algo automático y casi mágico, ligado a unos poderes maravillosos del celebrante y se convierte en humilde y confiada súplica de la Iglesia al Padre para que envíe al Espíritu santificador sobre los dones del pan y del vino.

Esta rica visión oriental contrasta con la parquedad pneumatológica del canon romano, donde la epíclesis está sólo implícita. En cambio, la Iglesia latina puso su énfasis en el relato de la institución y, cuando asumió la filosofía aristotélica, consideró que la consagración sucedía cuando las palabras de la institución (forma) se unían al pan y al vino (materia). Esto pasó al concilio de Florencia (DS 1321), en un texto que muchos no creen sea definitorio. Pero se inició una controversia entre occidente y oriente. Occidente puso la eficacia consacratoria en las palabras del relato de la institución; Oriente, en la epíclesis.

El Vaticano II, interpelado por oriente, ha introducido la epíclesis, en sus nuevas plegarias eucarísticas, y hoy ya no se discute sobre la cronología de la consagración, sino que, con una visión más integral, se afirma que tanto la epíclesis como el relato de la institución son elementos determinantes para la transformación de los dones, en el cuerpo y la sangre de Cristo. En el fondo, hay que mantener la fecunda tensión y reciprocidad entre cristología y pneumatología, entre el Hijo y el Espíritu, que son las dos manos con las que el Padre nos moldea, como dice bellamente Ireneo de Lyón.

16. N. Pertile, Manifestado pelo Espírito Santo; Paul Evdokimov, “Teología sob o signo da Epiclese", Belo Horizonte, 2005, tesis doctoral no publicada. 


\section{Eucaristía e Iglesia}

Mucho antes del Vaticano II, H. de Lubac ya había recordado la tradición bíblica y patrística, sobre todo agustiniana, de la eucaristía como sacramento de la unidad de la Iglesia, "signo de unidad, vínculo de caridad"17. El mismo autor proponía los resultados de su investigación histórica, que parecieron sorprendentes a algunos, sobre la expresión "cuerpo místico" (de Cristo). Al comienzo de la edad media, "cuerpo místico" significaba la eucaristía, pero al final de mismo período vino a significar la Iglesia, mientras que la expresión "cuerpo verdadero" (de Cristo), que al principio se refería a la Iglesia, pasó luego a referirse a la eucaristía ${ }^{18}$.

También en su célebre libro Meditación sobre la Iglesia', escrito en momentos en que $\mathrm{H}$. de Lubac era sospechoso de dudosa ortodoxia y destituido de su cátedra de Lyón, fraguó una expresión, de raíces patrísticas, que hizo fortuna: "La Iglesia hace la eucaristía, la eucaristía hace la Iglesia". Es decir, hay una estrecha conexión entre la eucaristía y la Iglesia. Así, se superaba la separación entre sacrificio y sacramento, que provenía de la postura de Trento contra la reforma. La eucaristía es el sacramento de la Iglesia.

Esta nueva orientación quedó plasmada en diversos lugares del Vaticano II, que ve la eucaristía como fuente y cumbre de la vida y actividad eclesial (SC 10; $L G$ 11). La obra de salvación realizada por Cristo se prolonga en la Iglesia, gracias a la liturgia (SC 5-6).

Esto llevará también a profundizar la relación entre el presidente de la eucaristía y la Iglesia, llegándose a la convicción que provenía de la Iglesia primitiva: "el que preside la Iglesia, preside la eucaristía", es decir, se preside la eucaristía, precisamente, porque se preside la Iglesia ${ }^{20}$. Ya el Vaticano II había dicho que el ministro sacerdotal en la eucaristía realiza las veces de Cristo (in persona Christi) y la ofrece a Dios, en nombre de todo el pueblo (nomine torius populi, $L G 10,2$ ).

Entre los autores del postconcilio que más han reflexionado sobre la relación entre eucaristía e Iglesia está J. M. R. Tillard, uno de cuyos libros tiene un título bien significativo Carne de Iglesia, carne de Cristo ${ }^{21}$.

Finalmente, citemos la encíclica de Juan Pablo II Ecclesia de eucaristía (2003), donde afirma claramente que la eucaristía edifica la Iglesia, citando de forma

17. H. de Lubac, Casholicisme, Paris, 1952.

18. H. de Lubac, Corpus mysticum. L'eucharistie et I'Église au Moyen Age, París, 1949.

19. H. de Lubac, Méditation sur l'Église, París, 1953.

20. H. M. Legrand, "La présidence de I'eucharistie selon la Ttradition ancienne", Spiritus 69 (1977) 409-43I.

21. J. M. R. Tillard, Carne de Iglesia, carne de Cristo, Salamanca, 1996. Ver también M. Gesteira, La eucaristía misterio de comunión, Madrid, 1983. 
explícita la afirmación de De Lubac "la Iglesia hace la eucaristía, la eucaristía hace la Iglesia". Y dentro del año de la eucaristía, proclamado por Juan Pablo II, W. Kasper ha publicado una nueva reflexión sobre la eucaristía y la Iglesia, resaltando sus dimensiones y consecuencias ecuménicas ${ }^{22}$.

\section{7 . Lex orandi, lex credendi}

Este antiguo axioma significa que la forma de orar establece la forma de cree $^{23}$, y ha servido de base para elaborar una teología de la eucaristía, partiendo de su liturgia, como lugar teológico privilegiado. Ya hemos empleado esta metodología, al hablar del memorial y de la epíclesis. Pero se pude ampliar a toda la plegaria eucarística.

El interés por conocer la plegaria eucarística ha llevado a realizar no sólo estudios históricos, como el clásico de J. A. Jungmann sobre la liturgia romana ${ }^{24}$, sino sobre todo a estudios estrictamente teológicos (L. Ligier, P. Audet, L. Bouyer, L. Maldonado y S. Marsili).

Para centramos en un autor reciente, asumiremos las conclusiones teológicas de C. Giraudo, que ha elaborado un tratado mistagógico de la eucaristía, a partir de las plegarias eucarísticas de oriente y occidente ${ }^{25}$. Giraudo contrapone la tcología eucarística del primer milenio, rezada en la Iglesia, a la teología eucarística del segundo milenio, estudiada en las aulas académicas. Es decir, la teología eucarística de los padres de la Iglesia, sobre todo en sus catequesis mistagógicas, era una explicación de la celebración eucarística de la que participaban los ne6fitos. Esto da a la teología un carácter vital y dinámico, sin separarla de la oración de la Iglesia, el lugar teológico privilegiado para comprender la eucaristía. Así, Giraudo insiste en que el sentido último de la eucaristía se desprende claramente de la segunda epíclesis, en la cual se pide que los participantes en ella se conviertan en el cuerpo de Cristo, que es la Iglesia. La conexión entre eucaristía e Iglesia, de la que hemos hablado antes, halla en la epíclesis su fundamento litúrgico.

Esto ha llevado también a estudiar la liturgia judía de la berakah, cuya estructura se mantiene sustancialmente, en nuestra liturgia cristiana. Acción de gracias, epíclesis, relato de la institución, mernorial, intercesión, comunión, se inscriben en una trayectoria litúrgica de la oración de la Iglesia, sin que su sentido último pierda el contexto celebrativo de ésta, su verdadera matriz.

22. W. Kasper, Sacramento dell'unità, Brescia, 2004.

23. Su formulación original "legem credendi lex statuat supplicandi", forma parte del Indiculus (DS 246) y su autor parece ser Próspero de Aquitania, secretario del papa León Magno, hacia 435.

24. J. A. Jungmann, Misarum sollemnia, Freiburg, 1962.

25. C. Giraudo, In unum corpus. Tratatto mistagógico sull'eucaristia, Milán, 2001. Hay un breve resumen del mismo autor, Conoci davvero l'eucaristía?, Magnano, $200 \mathrm{l}$. 


\section{Acercamiento ecuménico}

Todos estos trabajos teologicos han propiciado un acercamiento ecuménico con las iglesias de la reforma, con las cuales, desde el siglo XVI, hubo profundas diferencias, en tomo a la eucaristía. Los encuentros y documentos de Bristol (1968), Dombes (1971), Windsor (1971), Accra (1974) y Lima (1982) han supuesto grandes avances ecuménicos, en materia eucarística. Hay acuerdo en aceptar las dimensiones de banquete del Señor, memorial del sacrificio de Cristo, epíclesis o invocación al Espíritu, presencia sacramental de Cristo - que es real, viva y operativa-, comunión con la Iglesia, tarea por la justicia y la paz en el mundo, anticipación del banquete escatológico del reino, búsqueda ecuménica de unidad eclesial. Sin embargo, todavía quedan cuestiones pendientes, como son la presencia real después de la celebración, la cuestión del ministro ordenado para presidir la eucaristía y el problema de la hospitalidad eucarística.

Según W. Kasper, teólogo y presidente del Consejo Pontificio para la Promoción de la Unidad de los Cristianos, hay que evitar tanto el optimismo progresista, que afimna que las dificultades ya han sido superadas, como el pesimismo integrista, que sólo ve muros de prohibición y separaciones. Estamos en un estadio intermedio ${ }^{26}$, en el cual se ha avanzado, pero queda aún mucho por recorrer para llegar a la plenitud de Cristo (Ef 4, 16). El ecumenismo está en un proceso de crecimiento, en un "intercambio de dones"27.

El hecho de que en la situación actual no sea posible, por amor a la verdad, que todos los cristianos nos reunamos en tomo a la única mesa del Señor, es una profunda herida, en su cuerpo, y un verdadero escándalo. El bautismo nos da a todos los cristianos una comunión real, aunque no plena. Para el Vaticano II (UR 8), la eucaristía y la unidad son inseparables. Se participa de la eucaristía en la comunidad eclesial, a la cual cada uno pertenece, y esto último excluye una hospitalidad eucaristica abierta a todos. Pero como la salvación es la suprema ley de la Iglesia, en la encíclica sobre el ecumenismo Ut unum sint, Juan Pablo II recuerda que los ministros católicos pueden administrar la eucaristía a otros cristianos, aunque no estén en plena comunión con la Iglesia católica, si desean ardientemente recibirla y manifiestan la fe que la Iglesia católica profesa sobre este sacramento ${ }^{23}$.

Cada eucaristía que se celebra anticipa escatológicamente la unidad de todos los pueblos en Cristo. El fin del ecumenismo consiste en que todos los discípulos de Cristo se reúnan, en tomo a la única mesa del Señor, participen del mismo pan y beban del mismo vino. Si la Iglesia es el sacramento de la unidad y de la paz del mundo ( $L G$ I), la eucaristía es el sacramento de esta unidad. Pero hay que pedir al Espíritu el don de esta plena unidad del mundo, de la Iglesia y de la eucaristía.

26. W. Kasper, Sacramento dell 'unità, Brescia, 2004, pp. $62 \mathrm{~s}$.

27. Juan Pablo II, Ut unum sint, 28; 57.

28. Juan Pablo II, Ut unum sint, 46. Lo retoma en Ecclesia de eucharistia, 46. 


\section{Desde los pobres}

Ordinariamente, los estudios sobre la eucaristía acaban en la dimensión eclesial y ecuménica: la eucaristía, sacramento de la unidad eclesial. El mismo Pablo VI, en Mysterium Fidei, al hablar de las diferentes presencias de Cristo, se limita al ámbito eclesial: palabra, comunidad, ministros, sacramentos. Tampoco el Vaticano II relaciona la eucaristía con la justicia social. La doctrina social de la Iglesia, que habla de justicia, nada dice sobre su conexión con la eucarístía ${ }^{29}$.

Una lectura de la Escritura y de la tradición desde la perspectiva de los pobres nos hace descubrir, sin embargo, verdades un tanto olvidadas. La pascua judía era el memorial del éxodo, que significa la gesta liberadora de Yahvé, al escuchar el clamor del pueblo oprimido (Ex 3). El evangelio del juicio final, nos habla de una misteriosa pero real presencia de Cristo, en los marginados que pasan hambre, están desnudos, están enfermos o prisioneros (Mt 25,31-45). Algunos teólogos, como J Pixley y C. Boff, creen que los pobres son el único sacramento absolutamente necesario para la salvación ${ }^{30}$, el octavo sacramento, según el obispo Casaldáliga ${ }^{31}$. La acogida a los pobres es la única condición necesaria exigida para entrar en el reino.

Ya vimos que en las comidas de Jesús de Nazaret, los pobres son alimentados con el pan material. En el discurso del pan de vida de Juan 6, 28-71, el anuncio de la eucaristía está precedido por la multiplicación de los panes (Jn 6 , 1-15), como significando que no se puede desligar la eucaristía del hambre del mundo. También es significativo que Juan, en lugar de la institución de la eucaristía, proponga el relato del lavatorio de los pies (Jn 13,1-20), donde el Señor invita al servicio fraterno, para que las comunidades cristianas no se limiten a repetir el gesto litúrgico, olvidando el profundo sentido social de la eucaristía.

Las comidas de Jesús, por otra parte, anticipan el banquete del reino, donde no habrá hambre, ni exclusión. La misma muerte de Jesús está ligada a su opción por los pobres y a su oposición al sistema político y religioso que los excluía. En los sumarios de los Hechos de la Iglesia de Jerusalén, la fracción del pan está unida a una comunión (koinonía), que se extiende a los pobres y anticipa así la Jerusalén celeste (Hech 2, 42-47; 4, 32-37). Pablo se indigna porque los corintios no comparten la mesa y dice que su reunión no es la cena del Señor ( 1 Cor 11,20). En la Iglesia primitiva, la eucaristía estaba estrechamente ligada a las ofrendas de los fieles para los pobres, huérfanos y viudas ${ }^{32}$ y a las predicaciones patrísticas sobre la justicia ${ }^{33}$.

29. V. Martínez, "El pan hecho justicia", en Sentido social de la eucaristía, I, Bogotá, 2003.

30, J. Pixley-C.Boff, Opción por los pobres, Madrid, 1986, p. 133.

31. P. Casaldáliga, Cantares de entera libertad, Managua, 1984, p. 73.

32. J. M. Castillo, "Donde no hay justicia no hay eucaristía", en Autores varios, Fe y justicia, Salamanca, 1981, pp. 135-171.

33. V. Codina, La fraccion del pan, Cochabamba, 2002, pp. 87-91. 
En la historia de la Iglesia latinoamericana hay que recordar que el primer grito profético a favor de los indígenas aconteció en una celebración eucarística, en La Española, cuando el dominico Antonio de Montesinos, en el adviento de 1511, denunció las injusticias de los conquistadores españoles contra los indígenas. Un sacerdote español, Bartolomé de Las Casas, que poseía esclavos indios, quedó profundamente escandalizado. Pero más tarde, meditando el texto de Eclesiástico 34, 22-23, en el cual se critica la ofrenda a Dios de los injustos, Las Casas cambió de vida, liberó a sus esclavos, se hizo dominico y, nombrado obispo, se convirtió en el gran defensor de los indígenas ${ }^{24}$.

Lo que el Vaticano II no dijo sobre la eucaristía y la justicia, lo expresó Medellín, al afirmar que no es suficiente el gesto litúrgico, sino que es preciso un compromiso de caridad $(9,3)$ con la realidad humana, el desarrollo y la promoción $(9,4)$. Puebla, al reafirmar la opción por los pobres (nn.1134-1165), abre caminos para una relectura de la eucaristía, desde esta perspectiva.

La teología latinoamericana de la liberación ha subrayado esta conexión entre eucaristía y justicia ${ }^{35}$. La misma praxis eucarística de América Latina se ha enriquecido desde esta clave teológica. Pensemos en las eucaristías de los encuentros de las comunidades eclesiales de base o en las eucaristías de Mons Oscar Romero, en El Salvador, en una de las cuales fue asesinado, en 1980.

Pero este enfoque latinoamericano se extiende hoy a otros ámbitos de la Iglesia universal ${ }^{36}$. Una prueba de ello es el reciente número de Concilium dedicado al tema "Hambre, pan y eucaristía"37.

El mismo Juan Pablo II, en su carta apostólica Mone nobiscum Domine, sobre el año eucarístico, invita a que esta celebración desemboque en práctica de la justicia y la solidaridad.

34. B. de Las Casas, Historia de las Indias, $I I$, c. 79, Madrid, 196I; II, pp. 356s. Véase el comentario de E. Dussel, "El pan de la celebración, signo comunitario de justicia", Concilium 172 (1982) 236-249.

35. G. Gutiérrez, Teología de la liberación, Salamanca, 1972, pp. 336-362; R. Avila, Apuntes sobre las implicaciones sociopolíicas de la eucaristía, Bogotá, 1977; V. Codina, "Sacramentos", en I. Ellacuría y J. Sobrino (eds.), Mysterium liberationis, Madrid, 1990, II, pp. 267-294; “La fracción del pan”, l, pp. 224-227; V. Martínez, Sentido social de la eucaristía, Bogotá, 2003,especialmente el tomo III, Acontecimiento de justicia, con amplia bibliografía.

36. C. Floristán, "Teología y pastoral de la eucaristía", en Autores varios, Teología y pastoral, Madrid, 1982; Ph. Rosato, "La transocialización de los elementos eucarísticos", Selecciones de Teología 163 (2003) 223-240; X. Basurko, Compartir el pan. De la misa a la eucaristia, San Sebastián, 1989; J. A. Pagola, La eucaristía, experiencia de amor y de justicia, Santander, 1990; J. M. Castillo, ver nota 32.

37. Concilium 310 (2005). 


\begin{abstract}
¿Por qué, pues, no hacer de este Año de la Eucaristía un tiempo en que las comunidades diocesanas y parroquiales se comprometan especialmente a afrontar con generosidad algunas de las múltiples pobrezas de nuestro mundo? Pienso en el drama del hambre que atormenta a cientos de millones de seres humanos, en las enfermedades que flagelan a los países en desarrollo, el trasiego de los emigrantes. Se trata de males que, si bien en diversa medida, afectan también a las naciones más opulentas. No podemos hacernos ilusiones: por el amor mutuo y, en particular, por la atención a los necesitados se nos reconocerá como verdaderos discípulos de Cristo ( $c f$. Jn 13, 35; Mt 25 , 31-46). En base a este criterio, se comprobará la autenticidad de nuestras celebraciones eucarísticas ${ }^{38}$.
\end{abstract}

\title{
10. A modo de conclusión
}

Si quisiéramos resumir estos nuevos enfoques teológicos sobre la eucaristía, podríamos decir que, bajo el simbolismo claro de que la eucaristía es un banquete, se desprenden tres líneas de fuerza:

(a) El misterio pascual, es decir la eucaristía es el memorial, que hace presente en la Iglesia el misterio pascual de la muerte y resurrección de Jesús.

(b) La Iglesia, la comunidad que celebra la eucaristía, es, a su vez, el fruto último de la eucaristía, formar el cuerpo del Señor, unir a todos los participantes en un solo cuerpo.

(c) El reino fue anunciado proféticamente, en las comidas de Jesús con pobres y pecadores y, de modo especial, en la última cena; cada eucaristía debe intentar anticipar este reino no sólo litúrgicamente, sino con el compromiso de todos por la justicia y la solidaridad.

Pero el agente misterioso que hace presente al resucitado, en la liturgia eucarística, une a los comulgantes en un solo cuerpo y lanza a la Iglesia a la realización del reino de Dios, anticipando los nuevos cielos y la nueva tierra, es el Espíritu santo, al que la Iglesia, en su plegaria eucarística, invoca con la epíclesis.

Es mucho lo que se ha avanzado, en estos últimos años. Pero a nosotros se nos dice lo que el ángel de Yahvé dijo a Elías, al ofrecerle pan y agua, en el desierto: "Levántate y come, porque todavia te queda un largo camino" (1 Re 19,7).

38. Juan Pablo II, Mane nobiscum Domine, 28. Cfr. tambien Ecclesia de eucharistia, 20, donde el papa habla de la dimensión social de la eucaristía. 